physicians using valproate. (Asconape JJ, Penry JK, Dreifuss FE et al. Valproate-associated pancreatitis. Epilepsia Jan/Feb 1993; 34: 177-183).

\title{
NEONATAL NEUROLOGY
}

\section{PROGNOSIS OF INTRAVENTRICULAR HEMORRHAGE}

The relationship of periventricular-intraventricular hemorrhage in infants of $<32$ weeks gestation to the occurrence of disability at 5 years of age was studied in a National Collaborative Survey in the Netherlands. Of 484 infants enrolled, all 304 survivors were examined at age 5 years; $26 \%$ of infants with severe hemorrhage and $67 \%$ with mild grades I/II survived the neonatal period. Of $85(28 \%)$ survivors with a disability, $27(9 \%)$ had a minor handicap and $23(8 \%)$ a major handicap. The handicap was recorded at the age of 5 but was not present at 2 years in 17 children, while 35 were handicapped at 2 years but not at 5 years. Children with grades I and II as well as III and IV had more disabilities and handicaps than children without hemorrhage. (van de Bor $\mathrm{M}$ et al. Outcome of periventricular-intraventricular haemorrhage at five years of age. Dev Med Child Neurol Jan 1993; 35 : 33-41). (Respond: Dr van de Bor, Division of Neonatology, Department of Paediatrics, University Hospital Leiden, PO Box 9600, 2300 RC Leiden, The Netherlands).

COMMENT. The small number of survivors with grades III and IV hemorrhage was attributed to the widely used policy in the Netherlands of withdrawing life-support from infants with severe cerebral damage. Of 65 in this category, 47 died in the neonatal period. At the 5 year evaluation, only $25 \%$ of the patients had had severe hemorrhage. Children with only mild hemorrhage had a significantly increased risk of disability at the age of 5 years. Patients with evidence of periventricular leukomalacia were excluded from this study.

\section{LOCAL ANESTHESIA IN NEONATAL LUMBAR PUNCTURE}

The success rate of lumbar punctures was compared in neonates allocated prospectively to 0.2 to $0.5 \mathrm{~mL}$ of $1 \%$ lidocaine anesthesia $(\mathrm{n}=48)$ or a control group $(\mathrm{n}=52)$ in a study at the Albany Medical College of Union University, Albany, New York. A struggling motion score increased during the lidocaine injection but decreased at the spinal needle insertion. Despite the decreased motion following lidocaine, the number of attempts per lumbar puncture, failure rate, and traumatic punctures were not different from the controls. The success rate was not dependent on the level of physician training. (Pinheiro JMB et al. Role of local anesthesia during lumbar puncture in neonates. Pediatrics Feb 1993; 91: 379-382). (Reprints: Dr Pinheiro, Dept of Pediatrics, Albany Medical Center A-101, Albany, NY 12208)

COMMENT. The authors advocate lidocaine anesthesia in neonatal LPs. 